\title{
Rethinking the role of alpha toxin in Clostridium perfringens-associated enteric diseases: a review on bovine necro-haemorrhagic enteritis
}

Evy Goossens ${ }^{1}$, Bonnie R. Valgaeren², Bart Pardon², Freddy Haesebrouck'1, Richard Ducatelle', Piet R. Deprez ${ }^{2}$ and Filip Van Immerseel ${ }^{1 *}$

\begin{abstract}
Bovine necro-haemorrhagic enteritis is an economically important disease caused by Clostridium perfringens type A strains. The disease mainly affects calves under intensive rearing conditions and is characterized by sudden death associated with small intestinal haemorrhage, necrosis and mucosal neutrophil infiltration. The common assumption that, when causing intestinal disease, C. perfringens relies upon specific, plasmid-encoded toxins, was recently challenged by the finding that alpha toxin, which is produced by all C. perfringens strains, is essential for necro-haemorrhagic enteritis. In addition to alpha toxin, other C. perfringens toxins and/or enzymes might contribute to the pathogenesis of necro-haemorrhagic enteritis. These additional virulence factors might contribute to breakdown of the protective mucus layer during initial stage of pathogenesis, after which alpha toxin, either or not in synergy with other toxins such as perfringolysin $\mathrm{O}$, can act on the mucosal tissue. Furthermore, alpha toxin alone does not cause intestinal necrosis, indicating that other virulence factors might be needed to cause the extensive tissue necrosis observed in necro-haemorrhagic enteritis. This review summarizes recent research that has increased our understanding of the pathogenesis of bovine necro-haemorrhagic enteritis and provides information that is indispensable for the development of novel control strategies, including vaccines.
\end{abstract}

\section{Table of Contents}

1 Introduction

2 Aetiology

3 Epidemiology

3.1 Prevalence

3.2 Predisposing factors

3.2.1 Nutrition

3.2.2 Stress and intestinal homeostasis

4. Clinical signs and lesions

4.1 Clinical signs
4.2 Macroscopic lesions

4.3 Microscopic lesions

5 Virulence factors involved in disease

5.1 Beta2 toxin, a prime suspect of enteric diseases?

5.2 Alpha toxin, a critical role in pathogenesis?

5.3 Perfringolysin O

5.4 A role for proteolytic or carbohydrate-active enzymes?

5.4.1 Sialidases

5.4.2 Hyaluronidases

5.4.3 Collagenases

6 Pathogenesis: a hypothetical model

7 Diagnosis

8 Vaccination

9 Conclusions 


\section{Introduction}

Bovine necro-haemorrhagic enteritis caused by Clostridium perfringens is an important cause of sudden death with necro-haemorrhagic lesions in the small intestine. The disease typically affects calves in good to excellent body condition that are fed large amounts of milk or milk replacer, often without premonitory signs of illness. Although morbidity is rather low, mortality is close to $100 \%$, making it an economically important disease [1]. Despite the economic importance of the disease, until recently little was known about the pathogenesis of bovine necro-haemorrhagic enteritis. In the last few years, a series of papers have been published providing new insights in C. perfringens-associated bovine necrohaemorrhagic enteritis. Here, we review the knowledge on bovine necro-haemorrhagic enteritis, present a hypothetical model on the pathogenesis and discuss the current problems in vaccination.

\section{Aetiology}

Clostridium perfringens ranks amongst the most widespread bacteria, with an ubiquitous environmental distribution in soil, sewage, food, faeces, and the normal intestinal microbiota of humans and animals. This Gram-positive, anaerobic spore former is, however, also one of the most common pathogens, causing a spectrum of important human and animal diseases, ranging from myonecrotic to enteric infections [2, 3]. The virulence of $C$. perfringens is mediated by its intimidating arsenal of toxins and degradative enzymes. As a species, $C$. perfringens produces at least 16 toxins and extracellular enzymes [3-5]. However, no single strain produces this entire toxin panoply, resulting in considerable variation in the repertoire of toxins and degradative enzymes produced by different strains of this bacterium. These strain-to-strain differences in toxin production permits the classification of $C$. perfringens isolates into five toxinotypes (A, B, C, D and E), based on the presence of genes encoding four so-called major toxins: alpha, beta, epsilon and iota toxin [3]. Besides expressing one or more of the typing toxins, $C$. perfringens strains can produce additional toxins, including, but not limited to, enterotoxin and necrotic enteritis B-like toxin (NetB), which are also very important during certain diseases, for example human food poisoning or necrotic enteritis in broiler chickens $[5,6]$.

C. perfringens type A strains are the suspected aetiological agent of multiple bovine alimentary tract disorders. From these diseases, clostridial abomasitis and necrohaemorrhagic enteritis show remarkable similarities in aetiology, clinical symptoms, histological findings and predisposing factors. Even now, it is not clear whether they are truly different diseases or whether they should be considered as clinical or pathological variants of the same disease. For the completeness of this review, both diseases are included.

There is recent evidence clearly demonstrating that bovine necro-haemorrhagic enteritis is caused by C. perfringens type A strains. Indeed, the intestinal disease was reproduced by inoculation of bovine intestinal ligated loops with type A strains isolated from necro-haemorrhagic enteritis cases [7-9]. Furthermore, the causative role of $C$. perfringens type A in clostridial abomasitis was confirmed when intraruminal administration of $C$. perfringens type A to neonatal calves induced clinical signs similar to naturally acquired disease [10]. Almost exclusively toxinotype A strains are isolated from animals diagnosed with either necro-haemorrhagic enteritis [11-14] or clostridial abomasitis [10, 15, 16]. However, the involvement of this toxinotype and its toxin(s) was and still is heavily debated. As type A strains can be present in the normal intestinal microbiota, isolation of this toxinotype is not diagnostic for disease. Also detection of its major toxin, alpha toxin, has little diagnostic value, as it can be present in the faeces of healthy animals [17]. Therefore, diagnosis of enteric type A disease is not straightforward. Furthermore, also other toxinotypes can cause disease in cattle. C. perfringens type $C$ can cause sudden death in neonatal calves less than 10 days of age [18]. The intestinal lesions are similar to those described for type A, with severe necrosis and haemorrhages in the small intestine and neutrophil infiltration $[19,20]$. $C$. perfringens type $\mathrm{B}$ and $\mathrm{E}$ only sporadically cause disease. Only one report describing C. perfringens type B-associated disease in cattle was found. This report provides only limited information, but bloody diarrhoea, haemorrhagic enteritis and haemorrhages in all vital organs were described [21]. C. perfringens type $\mathrm{E}$ is considered an infrequent cause of haemorrhagic enteritis and sudden death in neonatal calves [22], however, one report also describes type $\mathrm{E}$ enterotoxaemia in adult cows [23]. Much research is focussed on the pathology caused by $C$. perfringens type $\mathrm{D}$ strains. Although $C$. perfringens type A and type D strains cause completely different pathologies, they both are commonly described as enterotoxaemia, making the nomenclature confusing $[7,9,12,21,22$, 24]. The term "enterotoxaemia" is widely applied to various diseases caused by C. perfringens, but it is appropriate only for diseases in which the major signs are caused by systemic actions of the toxins [25]. Indeed, type D enterotoxaemia is characterised by neurological signs without the presence of major intestinal lesions [26]. This is in contrast to the disease caused by type A strains, which is characterised by intestinal necrosis and haemorrhages, with neurological effects only sporadically being reported [27]. Therefore, we prefer to describe this syndrome as 
bovine necro-haemorrhagic enteritis, thereby making a clear distinction between the pathologies caused by $C$. perfringens type A or D, and clearly describing the lesions caused by the pathogen.

\section{Epidemiology}

\subsection{Prevalence}

Clostridial infection of the gastro-intestinal tract of cattle is a common problem all around the world [15, 16, 2830]. C. perfringens type A disease usually presents as individual sporadic cases. In young calves, $C$. perfringens type A disease mostly is characterized by abomasitis, often with lesions also in the upper part of the small intestine $[16,31]$. In older calves, $C$. perfringens type A causes necro-haemorrhagic enteritis. This disease can occur in cattle of all ages, but mainly affects suckling and veal calves in good to excellent body condition of up to four $[1,12,29]$ and eight months of age $[9,32]$ respectively. Although the disease is apparently widespread and the overall prevalence is unknown, there are differences in incidence between different breeds and production systems. Accurate data on the prevalence are only available for the disease in Belgium, where a mortality rate of $4.7 \%$ (accounting for approximately $50 \%$ of total mortality) has been reported in suckling calves [29]. The majority of the affected animals (89\%) are of the double muscled Belgian Blue beef cattle breed, suggesting a possible genetic influence for the susceptibility to necro-haemorrhagic enteritis. However, dairy breed calves are separated from the cow as soon as possible after birth and are typically not raised as suckling calves. Hence, as the majority of the affected animals are suckling calves, dietary influences can also be responsible for the difference in disease susceptibility. Also in veal calves, predominantly beef cattle breeds are affected, accounting for $20 \%$ of total mortalities on average, compared to $4 \%$ in dairy and mixed breed veal calves $[1,32]$. In addition to a possible breed influence, dietary differences between veal production systems are suspected to have a great effect as an eliciting factor [1, 32]. Whereas dairy breed veal calves receive milk powders with very little animal protein, beef cattle breeds receive a high amount of skimmed milk powder. An important risk period for bovine enterotoxaemia is situated at the end of the production cycle, where calves are fed high amounts of highly concentrated milk proteins [32]. Whereas dairy or traditional beef calves receive on average a maximum of 6 litres milk replacer per day at a concentration of $125 \mathrm{~g} / \mathrm{L}$, beef cattle breed veal calves receive at the end of fattening as much as $16 \mathrm{~L}$ daily, at a concentration ranging from 150 to $190 \mathrm{~g} / \mathrm{L}$. The predisposition of these calves may thus be linked to their higher feed, protein and energy intake.

\subsection{Predisposing factors \\ 3.2.1 Nutrition}

Since C. perfringens lacks many genes necessary for amino acid biosynthesis, it cannot grow in an environment where a specific amino acid supply is limited [33]. High dietary levels of digestible carbohydrates that exceed the digestion and absorption capacity of the intestinal mucosa can be utilized by $C$. perfringens to proliferate [34]. Indeed, previous studies have suggested that protein- and energy-rich diets predispose for this disease [1]. Dietary issues such as changes in feed composition, feed quantity, bringing animals to pasture or moving to a different pasture are often noted 24-36 h prior to death due to necrohaemorrhagic enteritis [29]. Also the ad libitum provision of concentrate feed to suckling calves predisposes for necro-haemorrhagic enteritis. The predisposition of both spring grass and feed concentrates might be attributed to the high protein concentration and low amount of fibres, which may alter the microbiota composition and favour clostridial overgrowth. By contrast, high fibre diets are often believed to protect from gastro-intestinal disease. Indeed, the reduction of the amount of concentrates provided to suckling calves and addition of dietary fibres reduced the incidence of necro-haemorrhagic enteritis [29]. In addition to feed concentrates and pasture, also cow's milk or milk replacer in the diet seems to predispose for C. perfringens-associated enteric diseases. Indeed, necro-haemorrhagic enteritis is more frequently observed in veal calves and suckler calves, and also neonatal calves are prone to abomasitis $[1,16,27,32]$. A common dietary factor in these populations is the high proportion of cow's milk or milk replacer in the diet. The whey present in cow's milk or milk replacer contains high quality, readily available amino-acids, potentially predisposing for clostridial overgrowth. We showed that milk replacer has an important predisposing effect in a ligated loop model for necro-haemorrhagic enteritis [35]. Furthermore, within the Belgian Blue breed, milk-fed veal calves produce less antibodies against $C$. perfringens alpha toxin than beef calves [36]. This suggests that calves fed cow's milk or milk replacer might have less contact with alpha toxin, leading to the absence of active immunity, and thus potentially leaving the calves unprotected against necrohaemorrhagic enteritis. Indeed, when $C$. perfringens is cultured in the presence of milk replacer, the alpha toxin activity of the supernatant decreases in a dose-dependent manner, compared to a negative control cultured without milk replacer [36, Supplemental file 1]. The observation that contact with milk decreases toxin expression seems in contradiction to the observation that high milk diets predispose for necro-haemorrhagic enteritis. However, the effect of milk on the $C$. perfringens production of 
mucinases, sialidases or other colonizing factors has not been investigated and might be of importance. Furthermore, the presence of crude proteins in the diet increases the mucin concentration in the small intestine [37]. This might favour colonization of the small intestinal mucus layer by $C$. perfringens and subsequent localized toxin production. Up till now the molecular mechanism behind the onset of necro-haemorrhagic enteritis is unknown. Furthermore, the role of feed in the pathogenesis of necro-haemorrhagic enteritis cannot be attributed to one specific factor, but to a very complex interaction of influences from a broad variety of fed components and their effect on and interaction with bacterial factors.

\subsubsection{Stress and intestinal homeostasis}

Stressful environmental conditions, such as regrouping, transport, handling and medical treatments have been mentioned as risk factors for necro-haemorrhagic enteritis [1]. A post-stress modification of the intestinal microbiota by induction of a paralytic ileus is a well-known phenomenon [38-40]. This can lead to unadapted digestive processes, and consequently a higher availability of these nutrients for bacterial growth [41]. The finding of Manteca et al. that ganglia are degenerated in necrohaemorrhagic enteritis suggests a direct effect on intestinal motility, additional to the general paralytic effect of enteritis, leading to a vicious circle. The consequent intestinal stasis diminishes the flushing of bacteria and toxins, and can contribute to bacterial overgrowth and colonization of the intestinal mucus layer [29, 42].

\section{Clinical signs and lesions}

\subsection{Clinical signs}

One of the hallmarks of bovine necro-haemorrhagic enteritis and clostridial abomasitis is the speed of disease progression. In most cases, apparently healthy animals with an excellent body conformation are found dead. When premonitory signs prior to death are noticed by the farmer, death due to necro-haemorrhagic enteritis occurs within $5 \mathrm{~h}[9,29]$. In those cases, signs of cardiovascular shock, including a lateral recumbent position and cold extremities, are commonly observed. Less frequently, colic and respiratory distress are present, whereas nervous symptoms, distended abdomen and diarrhoea are rather rare $[1,9,29]$. Premonitory disease signs for clostridial abomasitis are less extensively described, but include colic and haemorrhagic diarrhoea $[16,43,44]$.

\subsection{Macroscopic lesions}

Post-mortem a remarkable and rapid meteorism (bloating, tympanites...) of the abdomen and rapid putrefaction with foul smell is typical. On necropsy, cases of necro-haemorrhagic enteritis are characterized by diffuse or localized small intestinal haemorrhage with abundant liquid haemorrhagic contents (Figure 1) [1, 9, 29]. The haemorrhagic nature of the intestinal content is limited to the diseased intestinal segment, suggesting a paralytic ileus. The affected region can range from $10 \mathrm{~cm}$ to the entire length of the small intestine and is most often located in the jejunum $[9,29]$. However, also the ileum and less frequently the caecum, colon or abomasum can be affected [29]. There is also gas accumulation and in the majority of the cases the mesenteric lymph nodes are enlarged. Less frequently, lesions in other internal organs, such as petechiae or congestion, which are typical for shock, are observed [1, 29]. In young calves lesions are mainly situated in the abomasum, whereby this syndrome is referred to as clostridial abomasitis. The lesions mainly comprise acute emphysematous and necrotizing haemorrhagic inflammation of the abomasal mucosa, with marked oedema in the lamina propria and
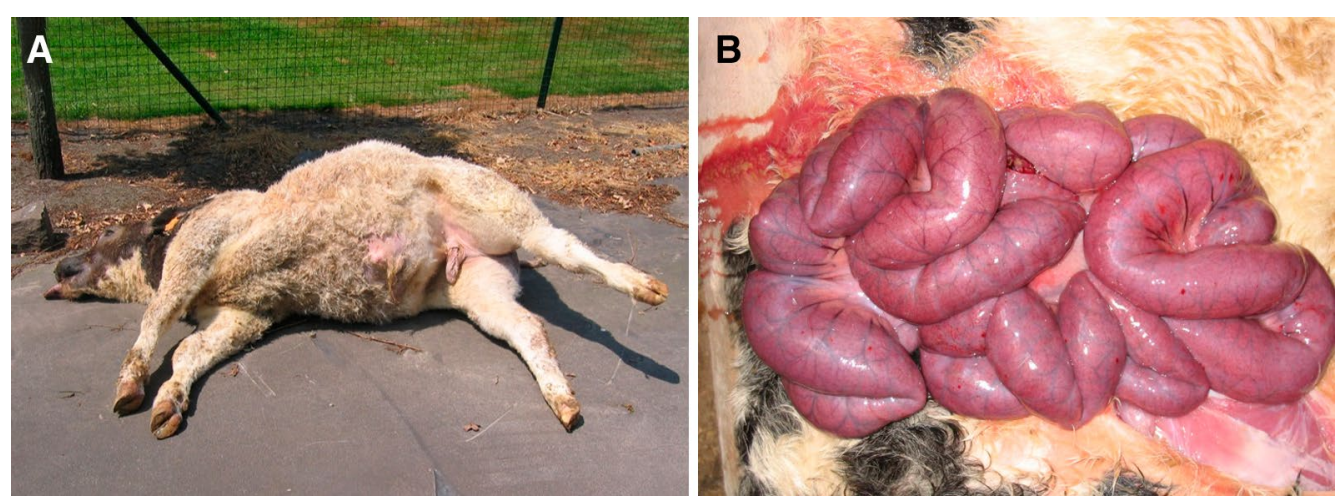

Figure 1 Post-mortem, macroscopic presentation of a case of bovine necro-haemorrhagic enteritis. A Acute death in a Belgian Blue calf with a distended abdomen and marked meteorism. B Severely dilated and congested small intestine of a case of bovine necro-haemorrhagic enteritis. When opening it is filled with blood. 


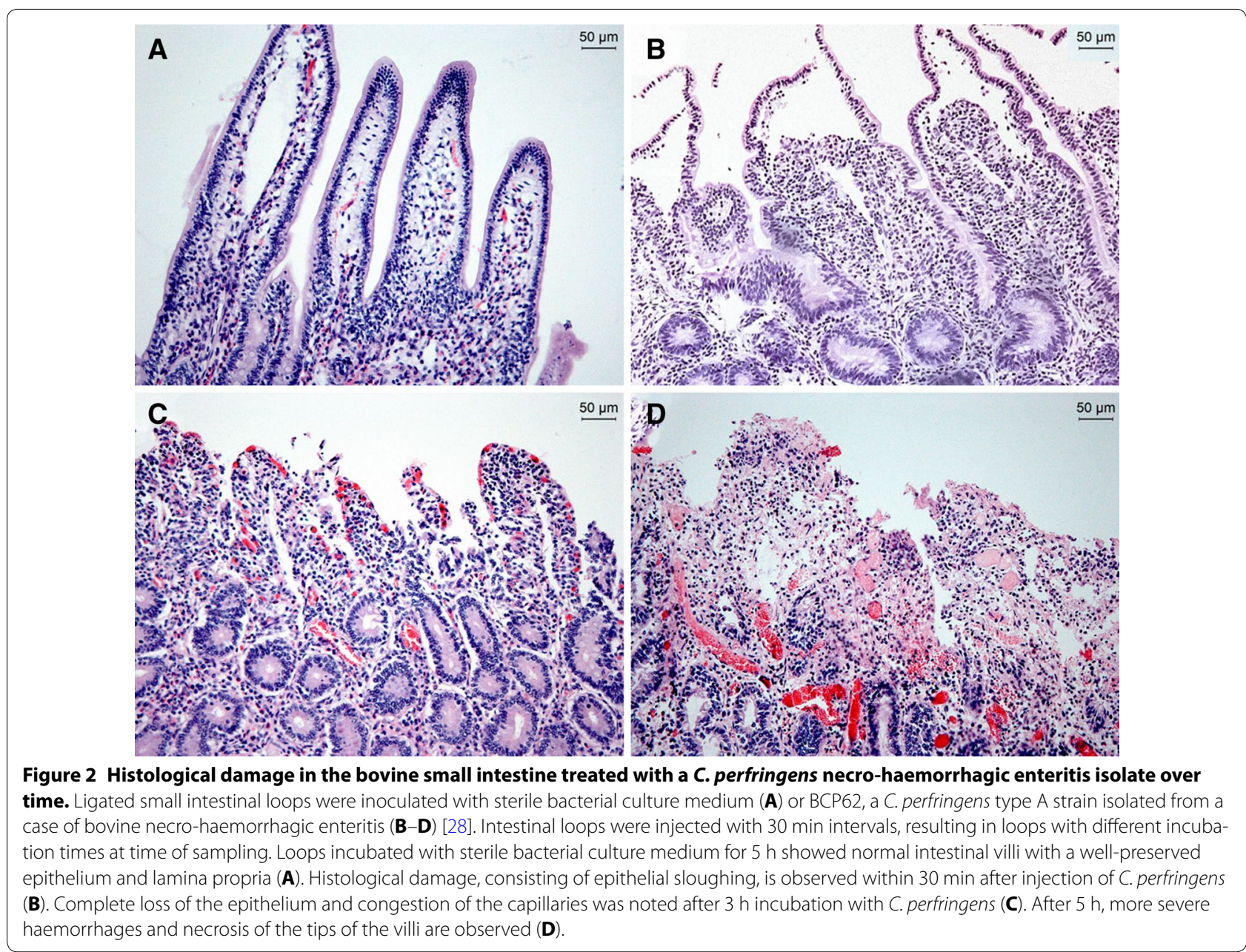

submucosa. Similar lesions are frequently present in the rumen, reticulum and duodenum $[10,16,43,44]$.

\subsection{Microscopic lesions}

Microscopic examination of necro-haemorrhagic enteritis cases reveals intestinal haemorrhages and cell necrosis extending from the tip of the villi to the base of the crypts, as well as infiltration of neutrophils and lymphocytes $[1,38]$. In the intestinal lumen, clusters of C. perfringens bacteria can be found, localized in the necrotic areas. However, they are typically not found in the mucosa of the intestinal wall [12]. Lesions typical for toxaemia are not consistently present in internal organs [12, 38 ]. We recently gained more insight into the sequence of histopathological events during lesion development using a calf intestinal loop model of necro-haemorrhagic enteritis (Figure 2) [35]. In early stages, only congestion of the capillaries and epithelial sloughing are observed, with strings of viable epithelium present in the lumen. One can argue that the observed detachment of epithelial cells is a result of post-mortem autolysis. However, control samples showed no sloughed epithelium, indicating the pathological nature of this event, which is in accordance with early lesions observed in C. perfringens-induced necrotic enteritis in broilers [45]. When the disease progresses, oedema of the mucosa, infiltration of inflammatory cells, villus blunting and haemorrhages occur, with necrosis only observed in advanced stages of disease. When severe necrosis is present, the necrotic tips of the villi are clearly separated from the underlying viable tissue. These observations indicate that the villi initially are damaged at the basement membrane and lateral domain of the enterocytes, followed by extensive damage to the lamina propria.

In contrast to necro-haemorrhagic enteritis, descriptions of microscopic changes in clostridial abomasitis are scanty. For clostridial abomasitis, mucosal haemorrhages, necrosis and variable degrees of inflammatory cell infiltration in the abomasum, with marked oedema in the lamina propria and submucosa are generally reported $[16,43,44]$. Experimental reproduction of disease has confirmed these histopathologic observations [10]. 


\section{Virulence factors involved in disease}

Although the role of other toxinotypes of C. perfringens in diseases originating in the intestine is well documented, the involvement of $C$. perfringens type A strains is rather controversial and often questioned. For many years, the involvement of $C$. perfringens type A strains in intestinal disorders was commonly accepted [3, 46-48]. More recently, the opinion in the scientific literature has shifted towards underrating the role of type A strains in enteric disease, leading to the postulation that type A strains are only important for myonecrotic infections (gas gangrene) and that enteric diseases in various animal species are generally caused by type B-E or type A subtypes, producing specific toxins such as enterotoxin and NetB $[49,50]$. In analogy with the recent discovery of subtypes of type A strains that produce newly identified toxins which are (potentially) involved in intestinal diseases in pigs, poultry and horses, it was suspected that a disease- and/or species-specific toxin was essential for the pathogenesis of $C$. perfringens type A-associated enteric disease in cattle as well.

\subsection{Beta2 toxin, a prime suspect of enteric diseases?}

Beta2 toxin is a pore-forming toxin that is associated with enteritis in neonatal pigs $[51,52]$ and gentamicinassociated diarrhoea in horses [53-55]. Beta2 toxin positive $C$. perfringens strains are widespread and can be isolated from various wild and domestic animals and humans, but also from food, soil and sludge [56-59]. $C$. perfringens type A strains harbouring the beta2 toxin gene have been isolated from diseased as well as healthy cattle of different ages $[8,59,60]$. However, there seem to be geographical differences in the reported number of beta 2 toxin positive isolates and up to now no unequivocal correlation between the isolation of beta2 toxin positive strains and gastro-intestinal disease in either calves or adult cattle could be demonstrated [7, 27, 44, 59]. A possible role of beta2 toxin in bovine enterotoxaemia was suggested in 2002 when Manteca et al. induced necrotic lesions with a beta2 toxin producing type A strain in a ligated loop experiment [7]. However, this was only tested in one intestinal loop in one calf, and the strain also produced large amounts of alpha toxin. In addition, no isogenic beta2 toxin-deficient strain was used as a control. Therefore, effects of other factors cannot be excluded. More recently, Morris et al. and Valgaeren et al. were able to induce necrotic lesions in an intestinal loop model by inoculation of type A strains not producing the beta 2 toxin $[8,35]$. Taking these results together with the observation that there is no correlation between the isolation of beta 2 toxin positive strains and the occurrence of disease [59], beta2 toxin seems not essential for the development of $C$. perfringens type A-associated gastro-intestinal diseases in cattle. However, a synergism between beta 2 toxin and other toxins is plausible and should be further investigated $[7,60]$. The actual role of beta 2 toxin in other enteric diseases is also not clear and recent papers suggest a limited role of beta2 toxin in disease [61] and that beta2 toxin positive C. perfringens type A strains merely reflect the normal intestinal microbiota [62].

\subsection{Alpha toxin, a critical role in pathogenesis?}

Alpha toxin is a phospholipase $C$ enzyme, which is preferentially active towards phosphatidylcholine and sphingomyelin, two major components of the outer leaflet of eukaryotic cell membranes [63]. This toxin is produced by all $C$. perfringens strains, although type A strains usually produce higher amounts than other toxinotypes. Alpha toxin is the major toxin produced by type A strains, but its role in intestinal diseases is controversial and heavily debated. Indeed, for over 30 years it was believed that alpha toxin was the key virulence factor in necrotic enteritis caused by $C$. perfringens in broiler chickens, until it was shown that a novel toxin, NetB, was crucial for disease [5, 64]. This is in contrast to the situation in cattle where incubation of numerous strains from different origin and toxinotypes in bovine ligated intestinal loops induced similar necro-haemorrhagic lesions, suggesting that common virulence factors rather than disease-specific toxins are essential [35]. Furthermore, analysis of the complete genome sequence of a bovine clostridial abomasitis isolate failed to reveal novel toxin genes [65]. Therefore a possible role of commonly produced toxins and/or virulence factors was suggested [35, 65]. Indeed, the importance of alpha toxin in the pathogenesis of bovine necro-haemorrhagic enteritis was demonstrated in a calf intestinal loop model, by using different approaches. First, an alpha toxin-mutant strain was attenuated in its lesion-inducing potential in the intestinal loop model, whereas complementation of alpha toxin restored its ability to cause necro-haemorrhagic lesions [66, 67]. Next, when antisera containing antibodies against native alpha toxin were co-injected with $C$. perfringens in bovine intestinal loops, the lesion-inducing potential of $C$. perfringens was reduced [66]. Furthermore, when pure alpha toxin was injected in bovine intestinal loops, it caused epithelial cell detachment, villus tip blunting, erosion, mild inflammation and haemorrhages of the lamina propria, all events that are seen in natural cases of necro-haemorrhagic enteritis [68].

In addition to a confirmed involvement of alpha toxin in bovine necro-haemorrhagic enteritis, this toxin might also play a role in enteric diseases in other animals, including humans [64, 69-75]. When combining the research data on alpha toxin in enteric diseases conducted 
in different animal species, a pathological mechanism of alpha toxin in $C$. perfringens type A-associated enteric disorders can be proposed. Histopathologically all these intestinal disorders are characterized by damage to the tips of the villi or epithelial cell detachment, congestion of the capillaries, mucosal oedema and necrosis. In most cases, also haemorrhages and mucosal inflammation with concomitant influx of inflammatory cells is reported [1, 76-79]. For some of these pathological findings, there is indirect evidence that alpha toxin is responsible. In small intestine explants of rabbits incubated with alpha toxin, this toxin causes detachment of the epithelial cells at the tip of the villi [80]. Epithelial sloughing was also observed when alpha toxin was inoculated in bovine intestinal loops [68]. Alpha toxin is able to upregulate the matrix metalloproteinase (MMP) expression of the host as seen in vitro. This increased host MMP activity may be related to derangement of normal epithelial growth and increased degradation of subepithelial matrix, possibly explaining the observed epithelial detachment [81]. Additionally, alpha toxin induces the production of tumor necrosis factor-alpha (TNF- $\alpha$ ) by mononuclear cells, which may contribute to epithelial sloughing. It has been shown that intraperitoneal or systemic administration of TNF- $\alpha$ to mice or intraduodenal TNF- $\alpha$ injection in rats induces pathological intestinal cell shedding and that dysregulated TNF- $\alpha$ production is highly important in driving epithelial damage as shown in mice $[82,83]$. Another characteristic of $C$. perfringens type A-associated intestinal diseases that can be a result of the alpha toxin activity is the influx of inflammatory cells. Neutrophilic inflammation of the small intestine has been observed after intragastric administration of alpha toxin to neonatal piglets and after alpha toxin injection in small intestinal loops of rats, sheep and calves $[68,84,85]$. This trafficking of inflammatory cells to the infected tissues seems contradictory to the observations in gas gangrene, where the leukocytes are trapped inside the blood vessels. However, this difference may be related to the concentration of alpha toxin in the tissue. In gas gangrene, alpha toxin is produced in the tissue, leading to high toxin concentrations at the site of infection. This is in contrast to intestinal infections, where alpha toxin is produced by $C$. perfringens in the intestinal lumen and enters the mucosa through a currently unknown mechanism. Little is known about the permeability of the intestinal mucosa to alpha toxin, but it is likely that lower concentrations will be present in the intestinal mucosa than in the infected muscle tissue during gas gangrene [2]. Alpha toxin is well known to cause upregulation of adhesion molecules and IL-8 expression in endothelial cells and leukocytes $[86,87]$. When present in excessively high concentrations as observed in mouse models of gas gangrene, these intercellular mediators alter the processes of leukocyte adherence and extravasation, resulting in impaired movement of inflammatory cells to the infected tissue [88]. However, physiological levels of upregulation lead to trafficking of neutrophils into the tissue space, as observed in intestinal C. perfringens type A infections. Furthermore, Otamiri et al. have shown that this neutrophil influx was caused by alpha toxin-induced activation of endogenous phospholipase $\mathrm{A}_{2}$ in the rat intestinal mucosa [85]. Activation of endogenous phospholipase $A_{2}$ can result in the generation of highly pro-inflammatory lysophosphatidic acid which can damage the mucosa. The mucosal damage can be aggravated by oxidants, proteolytic enzymes and cytotoxic proteins originating from the infiltrated neutrophils, and may be associated with increased mucosal permeability. Indeed, an alpha toxintriggered increase in intestinal permeability was shown in rats, rabbits, sheep and chickens [75, 80, 84, 85]. Additionally, alpha toxin induces the production of plateletactivating factor (PAF) and TNF- $\alpha$ by endothelial and mononuclear cells respectively, which likely contribute to the increased vascular permeability and oedema during C. perfringens infections $[89,90]$. This increased vascular permeability may explain the haemorrhages observed after C. perfringens type A infections in some species. Indeed, haemorrhages of the lamina propria were reproduced after alpha toxin inoculation in ligated loops of the bovine small intestine [68]. Furthermore, the lethal effect of intra venous administration of alpha toxin to mice is closely related to the release of TNF- $\alpha$ from mononuclear cells into the bloodstream [91]. It should be noted that, although alpha toxin is described as a necrotizing toxin, no intestinal necrosis could be observed in any of the experimental models mentioned before. However, a mutant strain devoid of alpha toxin is attenuated in its lesion-inducing potential when injected in bovine intestinal loops [66, 67]. Together, these findings strongly suggest that alpha toxin is essential, but a synergism with other factors is needed to cause the fulminant necrosis seen in natural cases of necro-haemorrhagic enteritis [66, 68]. Up till now, the nature of the additional virulence factors is unknown, but there is some indirect evidence pointing towards certain toxins and enzymes.

\subsection{Perfringolysin 0}

Perfringolysin $\mathrm{O}$ is a cholesterol-dependent cytolysin which is produced by nearly all $C$. perfringens strains $[92,93]$. This toxin is not considered essential for disease development, but seems to have an important accessory role in some diseases. Indeed, in a mouse model for gas gangrene it was found that perfringolysin $\mathrm{O}$ affects the host inflammatory response and is, at least partially, involved in tissue destruction. However, these effects were less pronounced than those elicited by alpha toxin 
and a synergistic effect between both toxins has been shown $[89,94,95]$. The role of perfringolysin $\mathrm{O}$ in $C$. perfringens type $\mathrm{A}$-associated intestinal diseases in cattle is not yet fully understood. In a recent study antisera from calves immunized with a mixture of $C$. perfringens toxins were able to protect against intestinal necrosis when co-injected with $C$. perfringens in bovine intestinal loops [96]. Antibodies towards alpha toxin and perfringolysin $\mathrm{O}$ were identified as the most abundant antibodies in the protective immune sera, suggesting a possible role of both toxins in intestinal lesion development [96]. Verherstraeten et al. recently demonstrated a synergistic cytotoxic effect between alpha toxin and perfringolysin $\mathrm{O}$ to bovine endothelial cells. However, a perfringolysin $\mathrm{O}$-deficient strain was still able to cause necrosis in calf ligated intestinal loops [67]. It should be noted that this does not exclude a possible accessory role of perfringolysin $\mathrm{O}$ in intestinal disease. Based on the knowledge obtained from gas gangrene, the effect of perfringolysin $\mathrm{O}$ is expected to be more subtle and further research should be focused on the host inflammatory response and more specific the neutrophil and macrophage influx into the lesions.

5.4 A role for proteolytic or carbohydrate-active enzymes? In addition to alpha toxin and perfringolysin $\mathrm{O}$ it cannot be excluded that the protection afforded by antisera derived from calves vaccinated with a mixture of $C$. perfringens toxins in bovine intestinal loops is due to other immunogenic proteins [96]. These additional virulence factors do not necessarily have to be toxins, but can equally well be proteins that confer a specific advantage to $C$. perfringens during intestinal colonization and/or infection.

\subsubsection{Sialidases}

C. perfringens needs to breach through the protective intestinal mucus layer before alpha toxin, either or not in synergy with other toxins, can act on the bovine intestinal tissue. The large, complex structure of mucins makes them targets for many proteases, glycosidases and sulphatases. Enzymatic digestion of the mucus layer provides access to readily available sources of carbon and enables bacteria to reach the epithelial surface. C. perfringens can produce many glycosidases which have a range of catalytic specificities that reflect their capacity to breakdown a diversity of host glycans [97-100]. Many of the studies concerning mucin-degrading enzymes were carried out specifically on sialidases. These enzymes cleave terminal sialic acids from sugar chains of glycoproteins, glycolipids, oligosaccharides, gangliosides and other sialoglycoconjugates. Sialic acids are especially abundant in the intestinal tract, where they are major constituents of mucins. In C. perfringens three sialidase enzymes have been reported, the large exo-sialidases NanI and NanJ, and a smaller intracellular NanH enzyme. Genome sequencing showed that the majority of strains carry all three sialidase-encoding genes [101]. The sialidases release sialic acid from higher order gangliosides and glycoproteins, probably for subsequent transport into the bacterial cell [102]. Furthermore, the release of sialic acid is an initial step in the sequential degradation of mucins, since the terminal location of sialic acid residues in the mucin oligosaccharide chains may prevent the action of other glycosidases [103]. In contrast with gut commensals, which appear to use sialidases primarily for nutrient acquisition, some pathogens, such as $C$. perfringens, also use sialidases to decrypt adhesins or toxin-binding sites [103]. Indeed, in studies on gas gangrene a synergy between alpha toxin and the NanI sialidase was observed $[104,105]$. In these experiments alpha toxin had greater pathological effects on cultured cells that had been pretreated with NanI. Intramuscular injection of both alpha toxin and NanI in mice confirmed this synergy in vivo [104]. This enhancement of alpha toxin activity by NanI is dependent on the presence of gangliosides on the surface of the cell. Cleavage of sialic acid from these gangliosides, which protrude from the cell surface, most likely allows better interaction of alpha toxin with its substrates at the cellular surface $[104,105]$. However, the use of either a nanI-mutant or nanJ-mutant strain showed that large sialidases are not essential for virulence in a mouse model for gas gangrene [105]. This, however, does not exclude the possibility that sialidases are involved in the pathogenesis of gas gangrene, because subtle effects that might be mediated by the sialidases are masked in this model $[49,105]$. In addition to a possible role in gas gangrene, the large sialidases may also be of importance during intestinal infections. Recent research suggests that NanI sialidase may contribute to intestinal attachment and colonization. This conclusion was based on the observation that NanI sialidase promotes the adherence of a $C$. perfringens type $A$, type $C$ and type D strains to enterocyte host cells in vitro [106, 107]. Furthermore, pre-treatment of sensitive cells with NanI sialidase enhanced the subsequent binding and cytotoxic effects of epsilon toxin, suggesting that the large sialidases of $C$. perfringens can act in synergy with this toxin during type D enterotoxaemia [106]. However, no difference in in vitro mucin-degrading activities between C. perfringens strains originating either from bovine necro-haemorrhagic enteritis cases, from healthy cattle isolates or from other animal species could be demonstrated [108]. This, however, does not exclude a possible role of mucin-degrading enzymes in intestinal pathogenesis as the production of virulence factors in vitro 
does not necessarily reflect the in vivo situation, where contact with host tissue might alter the $C$. perfringens toxin production. Next, not only enzymatic differences but also functional differences such as enhanced substrate binding or reduced sensitivity to intestinal proteolytic inactivation might confer selective advantage to the producing strain. The exact role of sialidases and other mucin-degrading enzymes in $C$. perfringens type A-associated intestinal diseases has not been explored. Because it seems very likely that colonization and degradation of the small intestinal mucus layer are a prerequisite for the onset of necro-haemorrhagic enteritis, the glycosidases employed by C. perfringens to cope with the mucosal surface are probably of great importance and future research should focus on upregulation of these enzymes after contact with host tissue, the role of mucin-degrading enzymes in intestinal colonization and enzyme stability in the intestinal tract.

\subsubsection{Hyaluronidases}

Hyaluronan can form highly viscous solutions and is a major constituent of the extracellular matrix, especially in soft connective tissue [109]. The viscous consistency usually provides resistance to penetration of infectious agents and their extracellular products. Hyaluronidases are produced by a number of bacteria that cause infections at mucosal surfaces [110]. Hyaluronidase-mediated degradation of hyaluronan decreases the viscosity, which results in increased permeability of the connective tissues and potentially increased spread of microorganisms and toxins through the connective tissues [110, 111]. Alternatively, hyaluronidase may degrade hyaluronan cell coatings, thereby allowing direct contact between the pathogens and the host cell surfaces. Furthermore, the end products of hyaluronidase degradation are disaccharides which can be used as nutrients by the pathogen [110]. In $C$. perfringens 5 hyaluronidase genes are described (nagH, nagI, nagI, nagK and nagL), which encode secreted enzymes [33]. Not much research has been done on the $C$. perfringens hyaluronidases. The best studied enzyme is mu toxin or $\mathrm{NagH}[112,113]$. By itself, mu toxin is a non-lethal toxin but it is thought to contribute to the pathogenesis of $C$. perfringens infections through the degradation of mucins and connective tissue [114]. Furthermore it facilitates the spread of alpha toxin, thereby potentiating its activity [112]. Because the C. perfringens hyaluronidases are not as well studied as the other $C$. perfringens toxins, no experimental evidence exists about the actual role of these enzymes in either gas gangrene or intestinal infections. Future research should elucidate whether contact with host cells causes upregulated hyaluronidase expression, and if bovine disease isolates show enhanced hyaluronidase activity or resistance to intestinal degradation as compared to other C. perfringens strains.

\subsubsection{Collagenases}

Collagen is widely distributed throughout the body and is an integral component of the connective tissues and the basal membranes. Collagen disruption by bacterial collagenases may result in the loss of tissue integrity and subsequent tissue necrosis [115]. C. perfringens can produce various collagenolytic enzymes with molecular masses ranging from $\approx 80$ to $\approx 120 \mathrm{kDa}[116,117]$. Historically, research was focused on the $80 \mathrm{kDa}$ collagenase, which was designated as kappa toxin $[116,118$, 119]. This $80 \mathrm{kDa}$ collagenase was lethal for mice after intravenous injection. Furthermore, it has haemorrhagic and dermonecrotic activities and it can cause extensive connective tissue destruction, suggesting a potential role in the pathogenesis of gas gangrene [119]. However, a positive correlation was not always found between the virulence of $C$. perfringens and the ability to produce collagenase, and anti-collagenase was not effective in preventing experimental gas gangrene in guinea pigs, nor did it enhance the protective properties of anti-alpha toxin [120]. From 1994 onwards, research has switched from the 80 to the $120 \mathrm{kDa}$ collagenase and the term kappa toxin is used to describe the $120 \mathrm{kDa}$ protein [116, $121,122]$. It is suggested that the $80 \mathrm{kDa}$ collagenase can be generated from the $120 \mathrm{kDa}$ protein, but no experimental evidence exists to support this hypothesis [123, 124]. As described above, collagenases could play a role in clostridial virulence in terms of spreading toxins and bacterial cells to host tissue, and in tissue necrosis. The use of a colA-mutant $C$. perfringens strain revealed that its $120 \mathrm{kDa}$ gene product is not essential for disease in a mouse model for gas gangrene [124]. However, studies using this model are limited given that the mouse gas gangrene model does not enable conclusions to be drawn about the early stages of the infection [49]. The role of C. perfringens collagenases in intestinal diseases is not yet explored. However, these enzymes are likely involved in multiple stages of necro-haemorrhagic enteritis: its action on the basal membrane might induce epithelial sloughing, whereas in later stage of disease, breakdown of the connective tissue might lead to massive tissue necrosis and the haemorrhagic nature of the $80 \mathrm{kDa}$ enzyme might contribute to the observed haemorrhages.

\section{Pathogenesis: a hypothetical model}

A hypothesis on the key events in C. perfringens type A-induced intestinal necrosis is summarized in Figure 3. Bovine necro-haemorrhagic enteritis is a disease in which a concerted action of $C$. perfringens enzymes and toxins induces epithelial and vascular permeability. 


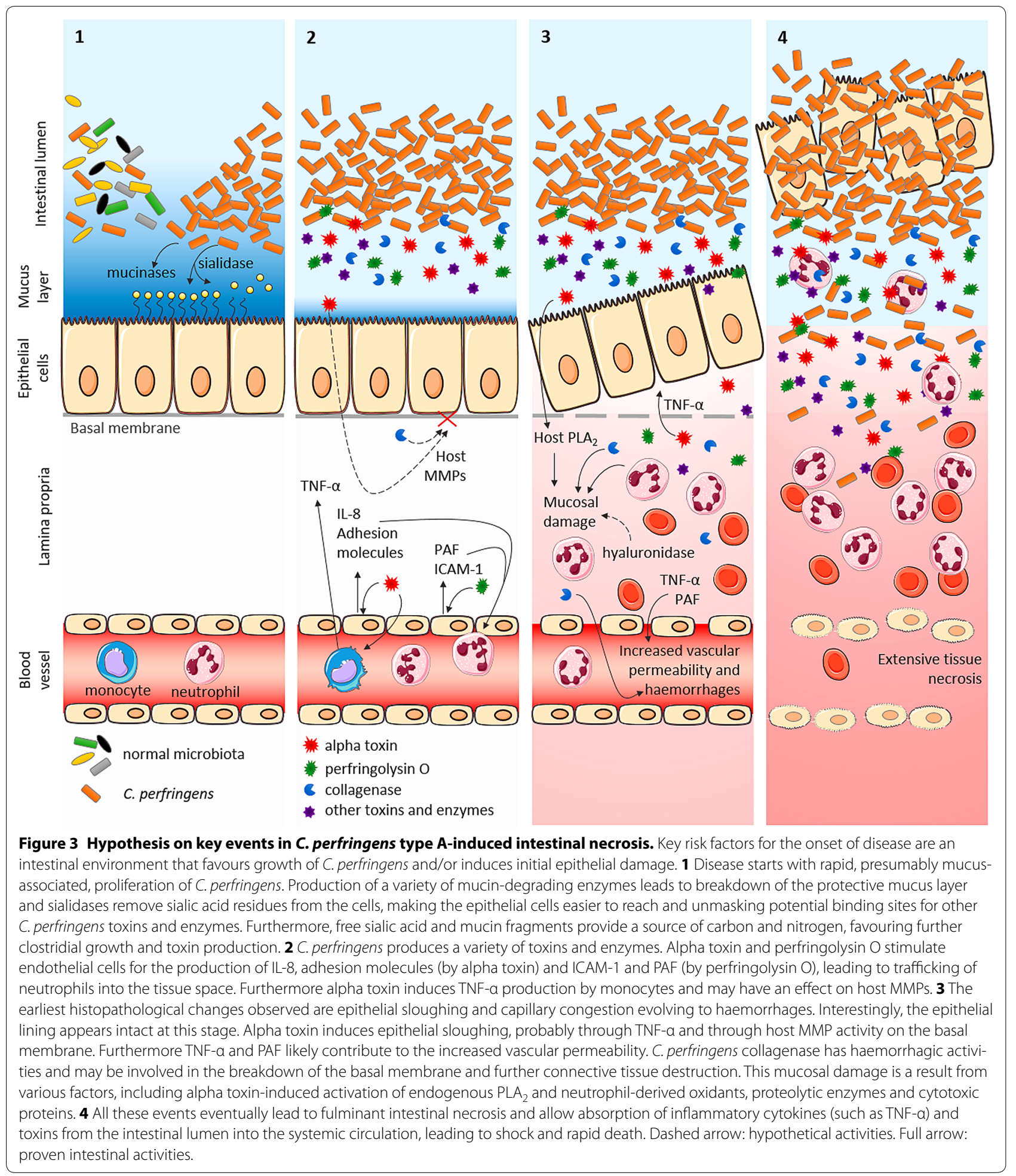

Subsequently the induced host responses and the action of bacterial components in the mucosa trigger intestinal inflammation, necrosis and haemorrhages. As C. perfringens type A strains are ubiquitous in the environment and are members of the normal intestinal microbiota, it is generally accepted that predisposing factors are required for $C$. perfringens to cause disease. Amongst the predisposing factors a high protein diet and stressful 
conditions are of major importance, but the exact mechanism behind this predisposition is still unclear. The most common hypothesis for the onset of C. perfringens-associated enteric diseases is the development of an intestinal environment that favours the growth of $C$. perfringens and triggers toxin production. However, when samples are taken shortly after death, no differences in intestinal C. perfringens counts were observed in calves who died from necro-haemorrhagic enteritis as compared to control calves $[9,27]$. There is increasing evidence that $C$. perfringens toxin production is upregulated upon sensing of host tissue, a process that is probably regulated by quorum sensing mechanisms [125-127]. Together, this suggests that elevated numbers of $C$. perfringens in the intestinal lumen are no prerequisite for disease development and that overgrowth in proximity to the intestinal epithelium might be of greater importance. Certain feed components can alter intestinal mucus secretion and increase the intestinal mucosal permeability [37, 128, 129]. Furthermore, the predisposing effect of stressful conditions might be attributed to an increased intestinal permeability, and an impaired intestinal peristalsis which cancels the beneficial flushing effect of intestinal transit and therefore may contribute to bacterial overgrowth and mucus colonization [12, 39, 40, 42]. The increased mucosal permeability may facilitate toxin penetration into the intestinal mucosa, which is needed to reach their target cells. C. perfringens itself also produces various mucin-degrading enzymes, which may lead to breakdown of the protective mucus layer and concomitant disturbance of the gut barrier. C. perfringens sialidases might remove sialic acid residues from the cells, making the epithelial cells easier to reach and unmasking potential binding sites for other toxins and enzymes [103, 104, 106, 107]. Furthermore, the free sialic acid and mucin fragments provide an energy source for $C$. perfringens growth and further toxin production. The earliest histopathological changes are shedding of epithelial cells into the intestinal lumen and congestion of the capillaries. Interestingly, the epithelial cells are detached in seemingly intact strings, suggesting that the first pathologic events are located at the basal membrane. Alpha toxin induces epithelial sloughing, probably through TNF- $\alpha$ and through host MMP activity on the basal membrane. Indeed, elevated host collagenase activities were previously observed in intestinal tissue of broilers [45] and calves (unpublished data) challenged with $C$. perfringens type A strains. Additionally also C. perfringens collagenases may be involved in breakdown of the basal membrane. When the epithelial barrier is breached, the various $C$. perfringens toxins and enzymes can penetrate the mucosa and reach their respective targets. C. perfringens hyaluronidase activity might increase the mucosal permeability and facilitate the spread of toxins through the connective tissue [111, 114]. Alpha toxin stimulates endothelial cells for the production of the neutrophil chemoattractant, interleukin-8 (IL-8), and two vasoactive lipids, PAF and prostacyclin. Furthermore, alpha toxin also induces the upregulation of adhesion molecules, both in endothelial cells and neutrophils [86, 87]. Perfringolysin $\mathrm{O}$ enhances the expression of pro-adhesive molecules on leukocytes, as well as ICAM-1 (intracellular adhesion molecule 1) and PAF on endothelial cells [87, 130, 131]. Together, these effects elicited by both alpha toxin and perfringolysin $\mathrm{O}$ contribute to the observed trafficking of neutrophils into the tissue space. Furthermore TNF- $\alpha$ and PAF likely contribute to the increased vascular permeability. $C$. perfringens collagenase has haemorrhagic activities and may also be involved in further destruction of the connective tissue. Thus mucosal damage results from the combined action of various factors, including the alpha toxin-induced activation of endogenous phospholipase $\mathrm{A}_{2}\left(\mathrm{PLA}_{2}\right)$, activity of C. perfringens hyaluronidase and other toxins and enzymes, and neutrophil-derived reactive oxygen species, proteolytic enzymes and cytotoxic proteins. All these events eventually lead to fulminant intestinal necrosis and allow the diffusion of inflammatory cytokines (such as TNF- $\alpha$ ) and toxins (e.g. LPS from Gram negative bacteria) from the intestine into the systemic circulation, leading to shock and rapid death. A systemic effect of alpha toxin in bovine intestinal diseases was never demonstrated and would not be considered great because alpha toxin is rapidly metabolised and eliminated from the blood stream [132].

\section{Diagnosis}

Despite the advances in the understanding of C. perfringens type A-associated enteric diseases, bovine necrohaemorrhagic enteritis remains a substantial diagnostic challenge. Overall, diagnosis of bovine necro-haemorrhagic enteritis cannot be confirmed by a specific test. The confirmation of a clinical suspicion of enterotoxaemia often remains difficult, and in atypical clinical presentations the diagnosis is often questionable. Therefore, multiple diagnostic techniques, including necropsy, histology of the intestine and bacteriology (including cultures for other causes of enteritis) should be combined and samples should be taken from the cadaver as soon as possible, ideally within $15 \mathrm{~min}$, to optimize chances for a correct diagnosis. Diagnosis of $C$. perfringens type A enteric diseases is complicated by the fact that type A strains are found in the gastrointestinal tract of healthy animals. Therefore, isolation of C. perfringens type A or detection of its major toxin, alpha toxin, from faeces or gastrointestinal content has little if any diagnostic value. 
Furthermore, $C$. perfringens strains isolated from necrohaemorrhagic enteritis cases cannot be differentiated from other $C$. perfringens type A strains in vitro with regard to their alpha toxin, perfringolysin $\mathrm{O}$ or proteolytic activities [108]. Enumeration of $C$. perfringens in the content of affected intestinal segments was historically recommended to confirm a clinical suspicion of necrohaemorrhagic enteritis. This practice was based on the presumption that clostridial enteric diseases are caused by a massive multiplication of $C$. perfringens in the gut, which was strengthened by a study suggesting higher $C$. perfringens load in intestinal content from calves that died from necro-haemorrhagic enteritis [133]. However, this study was biased by a large age difference between the control samples and the necro-haemorrhagic enteritis samples. This age difference will unavoidably imply dietary differences, which are known to influence the microbiota composition, questioning whether the observed differences in $C$. perfringens enumeration are really indicative for necro-haemorrhagic enteritis. Furthermore, $C$. perfringens multiplies in high numbers in the intestine as part of the post-mortem putrefaction process. More recently, enumeration of $C$. perfringens in necro-haemorrhagic enteritis samples and appropriate control samples revealed no differences in intestinal $C$. perfringens counts, even when samples were taken within $3 \mathrm{~h}$ after death, suggesting that $C$. perfringens enumeration in the intestinal content is not a valid diagnostic tool [9].

\section{Vaccination}

Clostridial diseases are often rapidly fatal. Therefore vaccination is usually the only achievable intervention. Most available clostridial vaccines are combination vaccines against several clostridial species, often including toxoids derived from multiple toxinotypes of $C$. perfringens. Amongst the $C$. perfringens toxinotypes, type $C$ and type $\mathrm{D}$ toxoids are almost always included in clostridial vaccines, whereas the other $C$. perfringens toxinotype toxoids are not always all included. In addition, toxoids from several other clostridial species are usually present in the vaccines: Clostridium chauvoei, Clostridium novyi, Clostridium sordellii, Clostridium septicum and Clostridium tetani. A few vaccines also include other bacteria such as Mannheimia haemolytica or enterotoxigenic Escherichia coli [1]. These toxoid-vaccines are made from culture supernatants which are inactivated, mostly using formaldehyde, and are subsequently subjected to an ultrafiltration purification process, which removes the bacterial cells and concentrates the desired antigens.

Until the recent demonstration of the essential role of alpha toxin in necro-haemorrhagic enteritis, not much attention was paid to alpha toxin in enteric diseases and its subsequent importance in vaccine composition.
However, it is well known that the protective antigenicity of alpha toxin is easily destroyed by formaldehyde inactivation [134-138], possibly explaining why the current clostridial vaccines are unable to protect against bovine necro-haemorrhagic enteritis $[29,96]$. Additional indirect evidence pointing towards the importance of alpha toxin as a vaccine antigen is the observation that calves in veal production systems do not develop an active immunity towards alpha toxin, when maternal immunity declines. This absence of antibody production after decay of maternal antibodies might explain why calves in veal production systems are at higher risk to develop necro-haemorrhagic enteritis than calves raised for beef production, in which a fluent transition from passive maternal to active immunity is observed $[32,36]$. The C-terminal domain of alpha toxin is a promising candidate for future vaccine development [66]. Indeed, the C-terminal fragment of alpha toxin is able to mount an immune response in calves and the resulting antisera show some protective properties against both $C$. perfringens-induced cytotoxicity and intestinal necrosis $[66,139]$.

Nevertheless, even if alpha toxin is indispensable to cause necro-haemorrhagic lesions, the presence of alpha toxin alone seems insufficient to cause the fulminant necrosis seen in natural cases $[66,68]$. Furthermore, when comparing antisera from calves immunized with alpha toxin alone versus antisera from calves vaccinated against a mixture of native $C$. perfringens toxins, the latter had a stronger ability to protect against C. perfringens-induced necrosis when co-injected with C. perfringens in bovine intestinal loops $[66,96]$. Therefore other virulence factors are likely involved as well in the pathogenesis and might be needed as vaccine components to provide full protection against bovine necro-haemorrhagic enteritis. Up till now the nature of the additional antigens which are needed to provide this protection is not clear. One possible candidate to include in future vaccines is perfringolysin O. Indeed, antibodies against both alpha toxin and perfringolysin $\mathrm{O}$ were detected in calf antisera that were able to protect against $C$. perfringens challenges in the intestinal loop model [96]. Furthermore, vaccination of calves with the non-toxic, perfringolysin $\mathrm{O}$ derivative $\mathrm{PFO}^{\mathrm{L} 491 \mathrm{D}}$ either or not in combination with the non-toxic, $\mathrm{C}$-terminal domain of alpha toxin, resulted in antibodies that were able to protect against the activities of the respective toxins in vitro [140]. More research is needed to elucidate whether addition of perfringolysin $\mathrm{O}$ as a vaccine antigen can increase the protective potential of the alpha toxin antisera against $C$. perfringens-induced intestinal lesions. Furthermore, it should be explored whether antibodies against other $C$. perfringens toxins or enzymes can also provide additional protection. 


\section{Conclusions}

The identification of alpha toxin as a key virulence factor in bovine necro-haemorrhagic enteritis provides some important novel insights. First, it clearly shows that the current view on $C$. perfringens-associated enteric diseases, which focusses mainly on plasmid-borne, disease-specific toxins is too strict and that alpha toxin can be important in enteric diseases. It is likely that even in diseases where other disease-specific toxins (e.g. NetB) are necessary to cause disease, alpha toxin might still be important in the pathogenesis. Second, the finding that alpha toxin is essential for necro-haemorrhagic enteritis has some major implications for vaccination strategies. The conformational epitopes of alpha toxin are important to induce a protective immune response and these epitopes are easily destroyed by formaldehyde. This adds to the understanding why current clostridial vaccines, which are based on formaldehyde inactivated toxins, don't seem to provide protection against $C$. perfringens type A-associated intestinal diseases in calves. In order to protect animals against $C$. perfringens type A-associated enteric disorders, novel vaccines are needed. Alpha toxin will probably be a key component in these vaccines and the non-toxic $\mathrm{C}$-terminal domain of alpha toxin may be a good candidate for further vaccine development. In addition, the ideal vaccine formulation should also contain other, yet unidentified, factors needed to provide full protection. These factors may be accessory toxins or enzymes involved in lesion induction, or factors that make the strains more adapted to the host environment. Next to vaccine formulation, also vaccination strategy may be important. Maternal immunization can be useful to protect young animals against clostridial abomasitis. An important risk period for the development of necro-haemorrhagic enteritis is situated near the end of the fattening period. In these older calves, maternal antibodies have declined and active immunization might be needed. Another important question is whether systemic immunity is sufficient to protect against $C$. perfringens type A-associated enteric diseases. Since C. perfringens is an enteric pathogen and given the local activity of its toxins, we could speculate that mucosal IgA plays a more important role than serum IgG in the protection against bovine necro-haemorrhagic enteritis. In cattle, no reports are found describing the mucosal IgA expression in the intestine during C. perfringens infection. Also for other species, the literature concerning this topic is scant. In humans, a correlation between the serum levels of IgA to alpha toxin and the faecal $C$. perfringens counts has been documented, but the relevance of this observation to provide protection against disease is not yet clear [141]. In chickens, it has been shown that systemic antibodies are able to reach the mucosal surface under inflammatory or necrotic conditions [137]. Furthermore, experimental animal work on intestinal $C$. difficile infections has shown that protection can be mediated through simple exudation of serum antitoxin IgG across the inflamed intestinal epithelium [142]. These observations point towards a serum IgG response as major influencer of protective immunity, but more research in cattle is needed to support this hypothesis. The ideal situation probably combines both systemic IgG as well as mucosal IgA immunity. This has been achieved using Bacillus subtilis spores as vaccine delivery agent. This organism is able to colonise the gut without causing disease. Oral immunization of mice with $B$. subtilis spores displaying the $\mathrm{C}$-terminal fragment of alpha toxin on the spore surface, resulted in increased serum IgG levels and secretory IgA detected in saliva, faeces or lung wash samples [143]. In addition to the use of $B$. subtilis spores, also the use of other intestinal organisms as antigen carriers can be explored, such as, amongst others, the use of Eimeria [144] or Salmonella [145]. Next, it should be investigated whether immunity against alpha toxin alone is sufficient when both systemic IgG as well as mucosal IgA immunity is obtained.

A major problem hindering vaccine development is the lack of an in vivo model. Despite multiple attempts by different research groups to reproduce bovine necrohaemorrhagic enteritis in vivo, the intestinal loop model remains the system closest to an intact animal that is able to reproduce the lesions consistently $[8,35$, $68,132]$. Because of the lack of an in vivo model, most research groups mainly focus on the development of an immune response as a readout for vaccine development [139]. However, antibody titres measured by ELISA are not a guarantee for protection and functional studies are more likely to predict the protective capacity of the elicited antibodies [96]. Indeed, screening of antibodies against the $C$. perfringens-induced cytotoxicity to bovine endothelial cells in vitro seems to give largely similar results as the protective effect of these antibodies against C. perfringens-induced intestinal lesions in bovine intestinal ligated loops $[66,96]$. As the susceptibility to different $C$. perfringens toxins varies between host species and tissues, results from one species cannot be extrapolated to other hosts $[68,132,146]$. While awaiting development of new vaccines, close monitoring and control of predisposing factors remains the best means to prevent necro-haemorrhagic enteritis.

\section{Abbreviations}

NetB: necrotic enteritis B-like toxin; MMP: matrix metalloproteinase; TNF-a: tumor necrosis factor-alpha; PAF: platelet activating factor; PLA $A_{2}$ : phospholipase $A_{2}$; IL-8: interleukin 8; ICAM-1: intracellular adhesion molecule 1; LPS: lipopolysaccharide. 


\section{Competing interests}

The authors declare that they have no competing interests.

\section{Authors' contributions}

$\mathrm{EG}, \mathrm{FH}$ and $\mathrm{FVI}$ designed the structure of the review; $\mathrm{EG}$ and $\mathrm{BV}$ drafted the manuscript; PD, BP, FH, FVI and RD critically revised the manuscript. All authors read and approved the final manuscript.

\section{Author details}

1 Department of Pathology, Bacteriology and Avian Diseases, Faculty of Veterinary Medicine, Ghent University, Salisburylaan 133, B-9820 Merelbeke, Belgium. ${ }^{2}$ Department of Large Animal Internal Medicine, Faculty of Veterinary Medicine, Ghent University, Salisburylaan 133, B-9820 Merelbeke, Belgium.

Received: 4 November 2016 Accepted: 12 January 2017

Published online: 16 February 2017

\section{References}

1. Lebrun M, Mainil JG, Linden A (2010) Cattle enterotoxaemia and Clostridium perfringens: description, diagnosis and prophylaxis. Vet Rec 167:13-22

2. Songer JG (1996) Clostridial enteric diseases of domestic animals. Clin Microbiol Rev 9:216-234

3. Petit L, Gibert M, Popoff MR (1999) Clostridium perfringens: toxinotype and genotype. Trends Microbiol 7:104-110

4. Hatheway CL (1990) Toxigenic clostridia. Clin Microbiol Rev 3:66-98

5. Keyburn AL, Boyce JD, Vaz P, Bannam TL, Ford ME, Parker D, Di Rubbo A, Rood JI, Moore RJ (2008) NetB, a new toxin that is associated with avian necrotic enteritis caused by Clostridium perfringens. PLoS Pathog 4:e26

6. Sarker MR, Carman RJ, McClane BA (1999) Inactivation of the gene (cpe) encoding Clostridium perfringens enterotoxin eliminates the ability of two cpe-positive C. perfringens type A human gastrointestinal disease isolates to affect rabbit ileal loops. Mol Microbiol 33:946-958

7. Manteca C, Daube G, Jauniaux T, Linden A, Pirson V, Detilleux J, Ginter A, Coppe P, Kaeckenbeeck A, Mainil JG (2002) A role for the Clostridium perfringens beta2 toxin in bovine enterotoxaemia? Vet Microbiol 86:191-202

8. Morris WE, Venzano AJ, Elizondo A, Vilte DA, Mercado EC, FernandezMiyakawa ME (2011) Necrotic enteritis in young calves. J Vet Diagn Invest 23:254-259

9. Valgaeren BR, Pardon B, Verherstraeten S, Goossens E, Timbermont L, Haesebrouck F, Ducatelle R, Deprez PR, Van Immerseel F (2013) Intestinal clostridial counts have no diagnostic value in the diagnosis of enterotoxaemia in veal calves. Vet Rec 172:237

10. Roeder BL, Chengappa MM, Nagaraja TG, Avery TB, Kennedy GA (1988) Experimental induction of abdominal tympany, abomasitis, and abomasal ulceration by intraruminal inoculation of Clostridium perfringens type A in neonatal calves. Am J Vet Res 49:201-207

11. Daube G, Simon P, Limbourg B, Manteca C, Mainil J, Kaeckenbeeck A (1996) Hybridization of 2659 Clostridium perfringens isolates with gene probes for seven toxins (alpha, beta, epsilon, iota, theta, mu, and enterotoxin) and for sialidase. Am J Vet Res 57:496-501

12. Manteca C, Daube G, Pirson V, Limbourg B, Kaeckenbeeck A, Mainil JG (2001) Bacterial intestinal flora associated with enterotoxaemia in Belgian Blue calves. Vet Microbiol 81:21-32

13. Niilo L, Avery RJ (1963) Bovine "enterotoxemia"I. Clostridium perfringens types isolated from animal sources in Alberta and Saskatchewan. Can Vet J 4:31-36

14. Yoo HS, Lee SU, Park KY, Park YH (1997) Molecular typing and epidemiological survey of prevalence of Clostridium perfringens types by multiplex PCR. J Clin Microbiol 35:228-232

15. Roeder BL, Chengappa MM, Nagaraja TG, Avery TB, Kennedy GA (1987) Isolation of Clostridium perfringens from neonatal calves with ruminal and abomasal tympany, abomasitis, and abomasal ulceration. Am J Vet Res 190:1550-1555

16. Songer GJ, Miskimins DW (2005) Clostridial abomasitis in calves: case report and review of the literature. Anaerobe 11:290-294

17. Deprez P (2015) Clostridium perfringens infections - a diagnostic challenge. Vet Rec 177:388-389
18. House JK, Smith GW, McGuirk SM, Gunn AA, Izzo M (2014) Manifestations and management of disease in neonatal ruminants. In: Smith BP (ed) Large animal internal medicine, vol 5. Mosby Elsevier, St, Louis

19. Garcia JP, Anderson M, Blanchard P, Mete A, Uzal FA (2013) The pathology of enterotoxemia by Clostridium perfringens type C in calves. J Vet Diagn Invest 25:438-442

20. Niilo L, Harries WN, Jones GA (1974) Clostridium perfringens type $C$ in hemorrhagic enterotoxemia of neonatal calves in Alberta. Can Vet J 15:224-226

21. Ehsan MA, Islam KS, Islam MA, Rahman AK, Ahmed S (2002) Characterization of type of Clostridium perfringens causing enterotoxaemia in cattle. Banglandesh Vet 19:86-91

22. Songer JG, Miskimmins DW (2004) Clostridium perfringens type E enteritis in calves: two cases and a brief review of the literature. Anaerobe 10:239-242

23. Redondo LM, Farber M, Venzano A, Jost BH, Parma YR, FernandezMiyakawa ME (2013) Sudden death syndrome in adult cows associated with Clostridium perfringens type E. Anaerobe 20:1-4

24. Jones AL, Dagleish MP, Caldow GL (2015) Clostridium perfringens type D enterotoxaemia in cattle: the diagnostic significance of intestinal epsilon toxin. Vet Rec 177:390

25. Michelsen PGE, Smith BP (2014) Diseases caused by Clostridium perfringens toxins (enterotoxemia; yellow lamb disease; lamb dysentery necrotic enteritis). In: Smith BP (ed) Large animal internal medicine, vol 5. Mosby Elsevier, St. Louis

26. Filho EJ, Carvalho AU, Assis RA, Lobato FF, Rachid MA, Carvalho AA, Ferreira PM, Nascimento RA, Fernandes AA, Vidal JE, Uzal FA (2009) Clinicopathologic features of experimental Clostridium perfringens type D enterotoxemia in cattle. Vet Pathol 46:1213-1220

27. Muylaert A, Lebrun M, Duprez JN, Labrozzo S, Theys H, Taminiau B, Mainil J (2010) Enterotoxaemia-like syndrome and Clostridium perfringens in veal calves. Vet Rec 167:64-65

28. Van Immerseel F, Pardon B, Maes S, Heyndrickx M, Timbermont L, Boyen F, Haesebrouck F, Ducatelle R, Deprez P (2010) Isolation of a clonal population of Clostridium perfringens type A from a Belgian Blue calf with abomasal ulceration. J Comp Pathol 143:289-293

29. Manteca C, Daube G, Jauniaux T, Limbourg B, Kaeckenbeeck A, Mainil J (2000) Étude de l'entérotoxémie bovine en Belgique. II. Epizootiologie élémentaire et pathologie descriptive. Ann Méd Vét 145:75-82 (in French)

30. Glock RD, DeGroot BD (1998) Sudden death of feedlot cattle. J Anim Sc 76:315-319

31. Uzal FA, Songer GJ, Prescott JF, Popoff MR (2016) Clostridial diseases of animals. Wiley, New York

32. Pardon B, De Bleecker K, Hostens M, Callens J, Dewulf J, Deprez P (2012) Longitudinal study on morbidity and mortality in white veal calves in Belgium. BMC Vet Res 8:26

33. Shimizu T, Ohtani K, Hirakawa H, Ohshima K, Yamashita A, Shiba T, Ogasawara N, Hattori M, Kuhara S, Hayashi H (2002) Complete genome sequence of Clostridium perfringens, an anaerobic flesh-eater. Proc Natl Acad Sci USA 99:996-1001

34. Allaart JG, van Asten AJ, Grone A (2013) Predisposing factors and prevention of Clostridium perfringens-associated enteritis. Comp Immunol Microbiol Infect Dis 36:449-464

35. Valgaeren B, Pardon B, Goossens E, Verherstraeten S, Schauvliege S, Timbermont L, Ducatelle R, Deprez P, Van Immerseel F (2013) Lesion development in a new intestinal loop model indicates the involvement of a shared Clostridium perfringens virulence factor in haemorrhagic enteritis in calves. J Comp Pathol 149:103-112

36. Valgaeren BR, Pardon B, Goossens E, Verherstraeten S, Roelandt S, Timbermont L, Van Der Vekens N, Stuyvaert S, Gille L, Van Driessche L, Haesebrouck F, Ducatelle R, Van Immerseel F, Deprez P (2015) Veal calves produce less antibodies against C. perfringens alpha toxin compared to beef calves. Toxins 7:2586-2597

37. Montagne L, Toullec R, Formal M, Lalles JP (2000) Influence of dietary protein level and origin on the flow of mucin along the small intestine of the preruminant calf. J Dairy Sci 83:2820-2828

38. Worrall EE, Natalia L, Ronohardjo P, Partoutomo S, Tarmudji (1987) Enterotoxaemia in water buffaloes caused by Clostridium perfringens type A. Vet Rec 121:278-279 
39. Monnikes H, Tebbe JJ, Hildebrandt M, Arck P, Osmanoglou E, Rose M, Klapp B, Wiedenmann B, Heymann-Monnikes I (2001) Role of stress in functional gastrointestinal disorders. Evidence for stressinduced alterations in gastrointestinal motility and sensitivity. Dig Dis 19:201-211

40. Huerta-Franco MR, Vargas-Luna M, Montes-Frausto JB, Morales-Mata I, Ramirez-Padilla L (2012) Effect of psychological stress on gastric motility assessed by electrical bio-impedance. World J Gastroenterol 18:5027-5033

41. Niilo L (1986) Experimental production of hemorrhagic enterotoxemia by Clostridium perfringens type $\mathrm{C}$ in maturing lambs. Can J Vet Res 50:32-35

42. Husebye $\mathrm{E}$ (2005) The pathogenesis of gastrointestinal bacterial overgrowth. Chemotherapy 51(Suppl 1):1-22

43. Van Kruiningen HJ, Nyaoke CA, Sidor IF, Fabis JJ, Hinckley LS, Lindell KA (2009) Clostridial abomasal disease in Connecticut dairy calves. Can Vet J 50:857-860

44. Schlegel BJ, Nowell VJ, Parreira VR, Soltes G, Prescott JF (2012) Toxinassociated and other genes in Clostridium perfringens type $A$ isolates from bovine clostridial abomasitis (BCA) and jejunal hemorrhage syndrome (JHS). Can J Vet Res 76:248-254

45. Olkowski AA, Wojnarowicz C, Chirino-Trejo M, Laarveld B, Sawicki G (2008) Sub-clinical necrotic enteritis in broiler chickens: novel etiological consideration based on ultra-structural and molecular changes in the intestinal tissue. Res Vet Sci 85:543-553

46. Uzal FA, Vidal JE, McClane BA, Gurjar AA (2010) Clostridium perfringens toxins involved in mammalian veterinary diseases. Open Toxinol J 2:24-42

47. Li J, Adams V, Bannam TL, Miyamoto K, Garcia JP, Uzal FA, Rood Jl, McClane BA (2013) Toxin plasmids of Clostridium perfringens. Microbiol Mol Biol Rev 77:208-233

48. Titball RW, Naylor CE, Miller J, Moss DS, Basak AK (2000) Opening of the active site of Clostridium perfringens alpha-toxin may be triggered by membrane binding. Int J Med Microbiol 290:357-361

49. Uzal FA, Freedman JC, Shrestha A, Theoret JR, Garcia J, Awad MM, Adams V, Moore RJ, Rood JI, McClane BA (2014) Towards an understanding of the role of Clostridium perfringens toxins in human and animal disease. Future Microbiol 9:361-377

50. Uzal FA, McClane BA, Cheung JK, Theoret J, Garcia JP, Moore RJ, Rood JI (2015) Animal models to study the pathogenesis of human and animal Clostridium perfringens infections. Vet Microbiol 179:23-33

51. Klaasen HL, Molkenboer MJ, Bakker J, Miserez R, Hani H, Frey J, Popoff MR, van den Bosch JF (1999) Detection of the beta2 toxin gene of Clostridium perfringens in diarrhoeic piglets in The Netherlands and Switzerland. FEMS Immunol Med Microbiol 24:325-332

52. Waters M, Savoie A, Garmory HS, Bueschel D, Popoff MR, Songer JG, Titball RW, McClane BA, Sarker MR (2003) Genotyping and phenotyping of beta2-toxigenic Clostridium perfringens fecal isolates associated with gastrointestinal diseases in piglets. J Clin Microbiol 41:3584-3591

53. Herholz C, Miserez R, Nicolet J, Frey J, Popoff M, Gibert M, Gerber H, Straub R (1999) Prevalence of beta2-toxigenic Clostridium perfringens in horses with intestinal disorders. J Clin Microbiol 37:358-361

54. Bacciarini LN, Boerlin P, Straub R, Frey J, Grone A (2003) Immunohistochemical localization of Clostridium perfringens beta2-toxin in the gastrointestinal tract of horses. Vet Pathol 40:376-381

55. Vilei EM, Schlatter Y, Perreten V, Straub R, Popoff MR, Gibert M, Grone A, Frey $J$ (2005) Antibiotic-induced expression of a cryptic cpb2 gene in equine beta2-toxigenic Clostridium perfringens. Mol Microbiol 57:1570-1581

56. Johansson A, Aspan A, Bagge E, Baverud V, Engstrom BE, Johansson KE (2006) Genetic diversity of Clostridium perfringens type A isolates from animals, food poisoning outbreaks and sludge. BMC Microbiol 6:47

57. Jost BH, Billington SJ, Trinh HT, Bueschel DM, Songer JG (2005) Atypical cpb2 genes, encoding beta2-toxin in Clostridium perfringens isolates of nonporcine origin. Infect Immun 73:652-656

58. Razmyar J, Kalidari GA, Tolooe A, Rad M, Movassaghi AR (2014) Genotyping of Clostridium perfringens isolated from healthy and diseased ostriches (Struthio camelus). Iran J Microbiol 6:31-36

59. van Asten AJ, Nikolaou GN, Grone A (2010) The occurrence of cpb2toxigenic Clostridium perfringens and the possible role of the beta2toxin in enteric disease of domestic animals, wild animals and humans. Vet J 183:135-140
60. Ceci L, Paradies P, Sasanelli M, de Caprariis D, Guarda F, Capucchio MT, Carelli G (2006) Haemorrhagic bowel syndrome in dairy cattle: possible role of Clostridium perfringens type A in the disease complex. J Vet Med A Physiol Pathol Clin Med 53:518-523

61. Allaart JG, van Asten AJ, Vernooij JC, Grone A (2014) Beta2 toxin is not involved in in vitro cell cytotoxicity caused by human and porcine cpb2-harbouring Clostridium perfringens. Vet Microbiol 171:132-138

62. Larsson J, Aspan A, Lindberg R, Grandon R, Baverud V, Fall N, Jacobson $M$ (2015) Pathological and bacteriological characterization of neonatal porcine diarrhoea of uncertain aetiology. J Med Microbiol 64:916-926

63. Sakurai J, Nagahama M, Oda M (2004) Clostridium perfringens alphatoxin: characterization and mode of action. J Biochem 136:569-574

64. Keyburn AL, Sheedy SA, Ford ME, Williamson MM, Awad MM, Rood $J$, Moore RJ (2006) Alpha-toxin of Clostridium perfringens is not an essential virulence factor in necrotic enteritis in chickens. Infect Immun 74:6496-6500

65. Nowell VJ, Kropinski AM, Songer JG, Maclnnes JI, Parreira VR, Prescott JF (2012) Genome sequencing and analysis of a type A Clostridium perfringens isolate from a case of bovine clostridial abomasitis. PLoS One 7:e32271

66. Goossens E, Verherstraeten S, Valgaeren BR, Pardon B, Timbermont L, Schauvliege S, Rodrigo-Mocholi D, Haesebrouck F, Ducatelle R, Deprez PR, Van Immerseel F (2016) The C-terminal domain of Clostridium perfringens alpha toxin as a vaccine candidate against bovine necrohemorrhagic enteritis. Vet Res 47:52

67. Verherstraeten $\mathrm{S}$, Goossens E, Valgaeren B, Pardon B, Timbermont L, Vermeulen K, Schauvliege S, Haesebrouck F, Ducatelle R, Deprez P, Van Immerseel F (2013) The synergistic necrohemorrhagic action of Clostridium perfringens perfringolysin and alpha toxin in the bovine intestine and against bovine endothelial cells. Vet Res 44:45

68. Morris WE, Dunleavy MV, Diodati J, Berra G, Fernandez-Miyakawa ME (2012) Effects of Clostridium perfringens alpha and epsilon toxins in the bovine gut. Anaerobe 18:143-147

69. Sobel J, Mixter CG, Kolhe P, Gupta A, Guarner J, Zaki S, Hoffman NA, Songer JG, Fremont-Smith M, Fischer M, Killgore G, Britz PH, MacDonald C (2005) Necrotizing enterocolitis associated with Clostridium perfringens type $A$ in previously healthy north american adults. J Am Coll Surg 201:48-56

70. Mutters NT, Stoffels S, Eisenbach C, Zimmermann S (2013) Ischaemic intestinal perforation complicated by Clostridium perfringens sepsis in a diabetic patient. Infection 41:1033-1035

71. Songer JG, Uzal FA (2005) Clostridial enteric infections in pigs. J Vet Diagn Invest 17:528-536

72. Titball RW, Naylor CE, Basak AK (1999) The Clostridium perfringens alphatoxin. Anaerobe 5:51-64

73. Songer JG, Glock RD (1998) Enteric infection of swine with Clostridium perfringens types A and C. Swine Health Prod 6:223-225

74. Rehman H, Awad WA, Lindner I, Hess M, Zentek J (2006) Clostridium perfringens alpha toxin affects electrophysiological properties of isolated jejunal mucosa of laying hens. Poult Sci 85:1298-1302

75. Rehman H, ljaz A, Specht A, Dill D, Hellweg P, Manner K, Zentek J (2009) In vitro effects of alpha toxin from Clostridium perfringens on the electrophysiological parameters of jejunal tissues from laying hens preincubated with inulin and N-acetyl-L-cysteine. Poult Sci 88:199-204

76. Songer GJ, Taylor DJ (2006) Clostridial infections. In: Straw BE, Zimmerman JJ, D'Allaire S, Taylor DJ (eds) Diseases of Swine, vol 9. Wiley, New York

77. Timbermont L, Haesebrouck F, Ducatelle R, Van Immerseel F (2011) Necrotic enteritis in broilers: an updated review on the pathogenesis. Avian Pathol 40:341-347

78. Owaki S, Kawabuchi S, Ikemitsu K, Shono H, Furuoka H (2015) Pathological findings of hemorrhagic bowel syndrome (HBS) in six dairy cattle cases. J Vet Med Sci 77:879-881

79. Elhanafy MM, French DD, Braun U (2013) Understanding jejunal hemorrhage syndrome. J Am Vet Med Assoc 243:352-358

80. Kamaras J, Murrell WG (2001) The effect of bacterial enterotoxins implicated in SIDS on the rabbit intestine. Pathology 33:187-196

81. Firth JD, Putnins EE, Larjava H, Uitto VJ (1997) Bacterial phospholipase C upregulates matrix metalloproteinase expression by cultured epithelial cells. Infect Immun 65:4931-4936 
82. Williams JM, Duckworth CA, Burkitt MD, Watson AJ, Campbell BJ, Pritchard DM (2015) Epithelial cell shedding and barrier function: a matter of life and death at the small intestinal villus tip. Vet Pathol 52:445-455

83. Guma M, Stepniak D, Shaked H, Spehlmann ME, Shenouda S, Cheroutre H, Vicente-Suarez I, Eckmann L, Kagnoff MF, Karin M (2011) Constitutive intestinal NF-kappaB does not trigger destructive inflammation unless accompanied by MAPK activation. J Exp Med 208:1889-1900

84. Fernandez Miyakawa ME, Uzal FA (2005) Morphologic and physiologic changes induced by Clostridium perfringens type A alpha toxin in the intestine of sheep. Am J Vet Res 66:251-255

85. Otamiri T (1989) Phospholipase C-mediated intestinal mucosal damage is ameliorated by quinacrine. Food Chem Toxicol 27:399-402

86. Bunting M, Lorant DE, Bryant AE, Zimmerman GA, McIntyre TM, Stevens DL, Prescott SM (1997) Alpha toxin from Clostridium perfringens induces proinflammatory changes in endothelial cells. J Clin Invest 100:565-574

87. Bryant AE, Stevens DL (1996) Phospholipase C and perfringolysin O from Clostridium perfringens upregulate endothelial cell-leukocyte adherence molecule 1 and intercellular leukocyte adherence molecule 1 expression and induce interleukin-8 synthesis in cultured human umbilical vein endothelial cells. Infect Immun 64:358-362

88. Stevens DL (2000) The pathogenesis of clostridial myonecrosis. Int J Med Microbiol 290:497-502

89. Stevens DL, Tweten RK, Awad MM, Rood Jl, Bryant AE (1997) Clostridial gas gangrene: evidence that alpha and theta toxins differentially modulate the immune response and induce acute tissue necrosis. J Infect Dis 176:189-195

90. Stevens DL, Troyer BE, Merrick DT, Mitten JE, Olson RD (1988) Lethal effects and cardiovascular effects of purified alpha- and theta-toxins from Clostridium perfringens. J Infect Dis 157:272-279

91. Oda M, Kihara A, Yoshioka H, Saito Y, Watanabe N, Uoo K, Higashihara M, Nagahama M, Koide N, Yokochi T, Sakurai J (2008) Effect of erythromycin on biological activities induced by Clostridium perfringens alphatoxin. J Pharmacol Exp Ther 327:934-940

92. Deguchi A, Miyamoto K, Kuwahara T, Miki Y, Kaneko I, Li J, McClane BA, Akimoto S (2009) Genetic characterization of type A enterotoxigenic Clostridium perfringens strains. PLoS One 4:e5598

93. Verherstraeten $S$, Goossens E, Valgaeren B, Pardon B, Timbermont L, Haesebrouck F, Ducatelle R, Deprez P, Wade KR, Tweten R, Van Immerseel $F$ (2015) Perfringolysin O: the underrated Clostridium perfringens toxin? Toxins 7:1702-1721

94. Awad MM, Bryant AE, Stevens DL, Rood JI (1995) Virulence studies on chromosomal alpha-toxin and theta-toxin mutants constructed by allelic exchange provide genetic evidence for the essential role of alpha-toxin in Clostridium perfringens-mediated gas gangrene. Mol Microbiol 15:191-202

95. Awad MM, Ellemor DM, Boyd RL, Emmins JJ, Rood JI (2001) Synergistic effects of alpha-toxin and perfringolysin $\mathrm{O}$ in Clostridium perfringensmediated gas gangrene. Infect Immun 69:7904-7910

96. Goossens E, Verherstraeten S, Valgaeren BR, Pardon B, Timbermont L, Schauvliege S, Rodrigo-Mocholi D, Haesebrouck F, Ducatelle R, Deprez PR, Van Immerseel F (2016) Toxin-neutralizing antibodies protect against Clostridium perfringens-induced necrosis in an intestinal loop model for bovine necrohemorrhagic enteritis. BMC Vet Res 12:101

97. Fan S, Zhang H, Chen X, Lu L, Xu L, Xiao M (2016) Cloning, characterization, and production of three alpha-L-fucosidases from Clostridium perfringens ATCC 13124. J Basic Microbiol 56:347-357

98. Ficko-Blean E, Stuart CP, Suits MD, Cid M, Tessier M, Woods RJ, Boraston AB (2012) Carbohydrate recognition by an architecturally complex alpha- $N$-acetylglucosaminidase from Clostridium perfringens. $\mathrm{PLOS}$ One 7:e33524

99. Ficko-Blean E, Gregg KJ, Adams JJ, Hehemann JH, Czjzek M, Smith SP, Boraston AB (2009) Portrait of an enzyme, a complete structural analysis of a multimodular beta- $\mathrm{N}$-acetylglucosaminidase from Clostridium perfringens. J Biol Chem 284:9876-9884

100. Fujita M, Tsuchida A, Hirata A, Kobayashi N, Goto K, Osumi K, Hirose Y, Nakayama J, Yamanoi T, Ashida H, Mizuno M (2011) Glycoside hydrolase family 89 alpha- $\mathrm{N}$-acetylglucosaminidase from Clostridium perfringens specifically acts on GlcNAc alpha1,4Gal beta1R at the non-reducing terminus of O-glycans in gastric mucin. J Biol Chem 286:6479-6489
101. Hassan KA, Elbourne LD, Tetu SG, Melville SB, Rood Jl, Paulsen IT (2015) Genomic analyses of Clostridium perfringens isolates from five toxinotypes. Res Microbiol 166:255-263

102. Walters DM, Stirewalt VL, Melville SB (1999) Cloning, sequence, and transcriptional regulation of the operon encoding a putative $\mathrm{N}$-acetylmannosamine-6-phosphate epimerase (nanE) and sialic acid lyase (nanA) in Clostridium perfringens. J Bacteriol 181:4526-4532

103. Juge N, Tailford L, Owen CD (2016) Sialidases from gut bacteria: a minireview. Biochem Soc Trans 44:166-175

104. Flores-Diaz M, Alape-Giron A, Clark G, Catimel B, Hirabayashi Y, Nice E, Gutierrez JM, Titball R, Thelestam M (2005) A cellular deficiency of gangliosides causes hypersensitivity to Clostridium perfringens phospholipase C. J Biol Chem 280:26680-26689

105. Chiarezza M, Lyras D, Pidot SJ, Flores-Diaz M, Awad MM, Kennedy CL, Cordner LM, Phumoonna T, Poon R, Hughes ML, Emmins JJ, AlapeGiron A, Rood JI (2009) The Nanl and NanJ sialidases of Clostridium perfringens are not essential for virulence. Infect Immun 77:4421-4428

106. Li J, Sayeed S, Robertson S, Chen J, McClane BA (2011) Sialidases affect the host cell adherence and epsilon toxin-induced cytotoxicity of Clostridium perfringens type D strain CN3718. PLoS Pathog 7:e1002429

107. Li J, McClane BA (2014) Contributions of Nanl sialidase to Caco-2 cell adherence by Clostridium perfringens type $A$ and $C$ strains causing human intestinal disease. Infect Immun 82:4620-4630

108. Goossens E, Verherstraeten S, Timbermont L, Valgaeren BR, Pardon B, Haesebrouck F, Ducatelle R, Deprez PR, Van Immerseel F (2014) Clostridium perfringens strains from bovine enterotoxemia cases are not superior in in vitro production of alpha toxin, perfringolysin $\mathrm{O}$ and proteolytic enzymes. BMC Vet Res 10:32

109. Kreil G (1995) Hyaluronidases - a group of neglected enzymes. Protein Sci 4:1666-1669

110. Hynes WL, Walton SL (2000) Hyaluronidases of Gram-positive bacteria. FEMS Microbiol Lett 183:201-207

111. Girish KS, Kemparaju K (2007) The magic glue hyaluronan and its eraser hyaluronidase: a biological overview. Life Sci 80:1921-1943

112. Canard B, Garnier T, Saint-Joanis B, Cole ST (1994) Molecular genetic analysis of the nagH gene encoding a hyaluronidase of Clostridium perfringens. Mol Gen Genet 243:215-224

113. Chitayat S, Adams JJ, Furness HS, Bayer EA, Smith SP (2008) The solution structure of the C-terminal modular pair from Clostridium perfringens mu-toxin reveals a noncellulosomal dockerin module. J Mol Biol 381:1202-1212

114. Ficko-Blean E, Boraston AB (2006) The interaction of a carbohydratebinding module from a Clostridium perfringens $\mathrm{N}$-acetyl-beta-hexosaminidase with its carbohydrate receptor. J Biol Chem 281:37748-37757

115. Harrington DJ (1996) Bacterial collagenases and collagen-degrading enzymes and their potential role in human disease. Infect Immun 64:1885-1891

116. Matsushita O, Yoshihara K, Katayama S, Minami J, Okabe A (1994) Purification and characterization of Clostridium perfringens 120-kilodalton collagenase and nucleotide sequence of the corresponding gene. J Bacteriol 176:149-156

117. Pruteanu M, Hyland NP, Clarke DJ, Kiely B, Shanahan F (2011) Degradation of the extracellular matrix components by bacterial-derived metalloproteases: implications for inflammatory bowel diseases. Inflamm Bowel Dis 17:1189-1200

118. Wolf U, Bauer D, Traub WH (1991) Collagenase of Clostridium perfringens type A: degradation of human complement component C1q. Zentralbl Bakteriol 276:27-35

119. Kameyama S, Akama K (1971) Purification and some properties of kappa toxin of Clostridium perfringens. Jpn J Med Sci Biol 24:9-23

120. Evans DG (1947) Anticollagenase in immunity to Cl. welchii type A infection. Br J Exp Pathol 28:24-30

121. Obana N, Shirahama Y, Abe K, Nakamura K (2010) Stabilization of Clostridium perfringens collagenase mRNA by VR-RNA-dependent cleavage in $5^{\prime}$ leader sequence. Mol Microbiol 77:1416-1428

122. Obana N, Nomura N, Nakamura K (2013) Structural requirement in Clostridium perfringens collagenase mRNA 5 'leader sequence for translational induction through small RNA-mRNA base pairing. J Bacteriol 195:2937-2946

123. Yoshihara K, Matsushita O, Minami J, Okabe A (1994) Cloning and nucleotide sequence analysis of the colH gene from Clostridium 
histolyticum encoding a collagenase and a gelatinase. J Bacteriol 176:6489-6496

124. Awad MM, Ellemor DM, Bryant AE, Matsushita O, Boyd RL, Stevens DL, Emmins JJ, Rood JI (2000) Construction and virulence testing of a collagenase mutant of Clostridium perfringens. Microb Pathog 28:107-117

125. Chen J, Ma M, Uzal FA, McClane BA (2014) Host cell-induced signaling causes Clostridium perfringens to upregulate production of toxins important for intestinal infections. Gut Microbes 5:96-107

126. Vidal JE, Ma M, Saputo J, Garcia J, Uzal FA, McClane BA (2012) Evidence that the Agr-like quorum sensing system regulates the toxin production, cytotoxicity and pathogenicity of Clostridium perfringens type C isolate CN3685. Mol Microbiol 83:179-194

127. Vidal JE, Ohtani K, Shimizu T, McClane BA (2009) Contact with enterocyte-like Caco-2 cells induces rapid upregulation of toxin production by Clostridium perfringens type $C$ isolates. Cell Microbiol 11:1306-1328

128. Barratt ME, Strachan PJ, Porter P (1978) Antibody mechanisms implicated in digestive disturbances following ingestion of soya protein in calves and piglets. Clin Exp Immunol 31:305-312

129. Kilshaw PJ, Slade H (1980) Passage of ingested protein into the blood during gastrointestinal hypersensitivity reactions-experiments in the preruminant calf. Clin Exp Immunol 41:575-582

130. Bryant AE, Bergstrom R, Zimmerman GA, Salyer JL, Hill HR, Tweten RK, Sato H, Stevens DL (1993) Clostridium perfringens invasiveness is enhanced by effects of theta toxin upon PMNL structure and function: the roles of leukocytotoxicity and expression of CD11/CD18 adherence glycoprotein. FEMS Immunol Med Microbiol 7:321-336

131. Whatley RE, Nelson P, Zimmerman GA, Stevens DL, Parker CJ, Mclntyre TM, Prescott SM (1989) The regulation of platelet-activating factor production in endothelial cells. The role of calcium and protein kinase C. J Biol Chem 264:6325-6333

132. Niilo L, Moffatt RE, Avery RJ (1963) Bovine "enterotoxemia". II. Experimental reproduction of the disease. Can Vet J 4:288-298

133. Philippeau C, Goncalves S, Julliand J (2004) Enterotoxaemia in Charolais cattle in Burgundy: new decision support tools to improve bacterial diagnosis and hypotheses of risk factors. Rech Ruminants 11:321-324 (in French)

134. Ito A (1968) Alpha toxoid of Clostridium perfringens. I. Purification and toxoiding of alpha toxin of C. perfringens. Jpn J Med Sci Biol 21:379-391

135. Maclennan JD (1962) The histotoxic clostridial infections of man. Bacteriol Rev 26:177-276
136. Titball RW (2005) Gas gangrene: an open and closed case. Microbiology 151:2821-2828

137. Kulkarni RR, Parreira VR, Sharif S, Prescott JF (2007) Immunization of broiler chickens against Clostridium perfringens-induced necrotic enteritis. Clin Vaccine Immunol 14:1070-1077

138. Titball RW (2009) Clostridium perfringens vaccines. Vaccine 27(Suppl 4):D44-D47

139. Jiang Z, De Y, Chang J, Wang F, Yu L (2014) Induction of potential protective immunity against enterotoxemia in calves by single or multiple recombinant Clostridium perfringens toxoids. Microbiol Immunol 58:621-627

140. Verherstraeten S, Goossens E, Valgaeren B, Pardon B, Timbermont L, Haesebrouck F, Ducatelle R, Deprez P, Van Immerseel F (2016) Non-toxic perfringolysin $\mathrm{O}$ and a-toxin derivatives as potential vaccine candidates against bovine necrohaemorrhagic enteritis. Vet J 217:89-94

141. Johnson S (1997) Antibody responses to clostridial infection in humans. Clin Infect Dis 25(Suppl 2):173-177

142. Ghose C, Kelly CP (2015) The prospect for vaccines to prevent Clostridium difficile infection. Infect Dis Clin North Am 29:145-162

143. Hoang TH, Hong HA, Clark GC, Titball RW, Cutting SM (2008) Recombinant Bacillus subtilis expressing the Clostridium perfringens alpha toxoid is a candidate orally delivered vaccine against necrotic enteritis. Infect Immun 76:5257-5265

144. Blake DP, Clark EL, Macdonald SE, Thenmozhi V, Kundu K, Garg R, Jatau ID, Ayoade S, Kawahara F, Moftah A, Reid AJ, Adebambo AO, Alvarez Zapata R, Srinivasa Rao AS, Thangaraj K, Banerjee PS, Dhinakar-Raj G, Raman M, Tomley FM (2015) Population, genetic, and antigenic diversity of the apicomplexan Eimeria tenella and their relevance to vaccine development. Proc Natl Acad Sci USA 112:E5343-E5350

145. Zekarias B, Mo H, Curtiss R 3rd (2008) Recombinant attenuated Salmonella enterica serovar typhimurium expressing the carboxy-terminal domain of alpha toxin from Clostridium perfringens induces protective responses against necrotic enteritis in chickens. Clin Vaccine Immunol 15:805-816

146. Fernandez-Miyakawa ME, Sayeed S, Fisher DJ, Poon R, Adams V, Rood JI, McClane BA, Saputo J, Uzal FA (2007) Development and application of an oral challenge mouse model for studying Clostridium perfringens type D infection. Infect Immun 75:4282-4288

\section{Submit your next manuscript to BioMed Central and we will help you at every step:}

- We accept pre-submission inquiries

- Our selector tool helps you to find the most relevant journal

- We provide round the clock customer support

- Convenient online submission

- Thorough peer review

- Inclusion in PubMed and all major indexing services

- Maximum visibility for your research

Submit your manuscript at www.biomedcentral.com/submit
(OioMed Central 